\title{
Surrogate endpoint for overall survival in assessment of adjuvant therapies after curative treatment for hepatocellular carcinoma: a re-analysis of meta-analyses of individual patients' data
}

\author{
Hong-Bo Huan ${ }^{1}$, Li-Li Wu ${ }^{1}$, Wan-Yee Lau ${ }^{1,2}$, Xu-Dong Wen ${ }^{1}$, Liang Zhang ${ }^{1}$, Da-Peng \\ Yang ${ }^{1}$, Xi-Shu Wang ${ }^{1}$, Ping Bie ${ }^{1}$ and Feng Xia ${ }^{1}$ \\ ${ }^{1}$ Institute of Hepatobiliary Surgery, Southwest Hospital, Third Military Medical University, Chongqing, China \\ ${ }^{2}$ Faculty of Medicine, The Chinese University of Hong Kong, Prince of Wales Hospital, Shatin, Hong Kong SAR, China \\ Correspondence to: Feng Xia, email: txzzxf@163.com
}

Keywords: hepatocellular carcinoma, overall survival, disease-free survival, surrogate endpoint

Received: April 28, 2017

Accepted: June 20, 2017

Published: June 29, 2017

Copyright: Huan et al. This is an open-access article distributed under the terms of the Creative Commons Attribution License 3.0 (CC BY 3.0), which permits unrestricted use, distribution, and reproduction in any medium, provided the original author and source are credited.

\section{ABSTRACT}

The gold standard endpoint to evaluate the effect of treatment for hepatocellular carcinoma (HCC) is overall survival (OS), but it requires a longer follow-up period to observe. This study aimed to identify whether disease-free survival (DFS) could be used as a surrogate endpoint for $0 S$ to assess the efficacy of adjuvant therapies after curative treatment (surgical resection and ablation) for HCC patients. A systematic review was conducted to identify trials about curative treatment combined with or without adjuvant therapies (interferon, IFN; or transarterial chemoembolization, TACE) for HCC. Total of 2211 patients' data from 17 trials were analyzed. At the individual study level, DFS was strongly correlated to OS $(\rho=0.988$ and $0.930,95 \%$ CI: $0.965-0.996$ and $0.806-0.976$ for the studies comparing Radiofrequency ablation (RFA) + TACE to RFA alone; and for the studies comparing curative treatment + IFN to curative treatment alone, respectively). At the trial level, the effects of treatment on DFS and OS were also strongly correlated to each other $(R=0.815$ and $0.854,95 \%$ CI: $0.536-0.934$ and $0.621-0.948$, respectively). In conclusion, DFS could be used as a potential surrogate endpoint for $0 S$ to assess the effect of adjuvant therapies after curative treatment for HCC.

\section{INTRODUCTION}

Liver cancer is the second most common cause of cancer-related death, with 782,500 new cases and 745,500 cancer deaths occurred in 2012 worldwide [1]. As the major histological subtype, hepatocellular carcinoma (HCC) occupies $70 \%$ to $85 \%$ of patients with liver cancers [2]. During the past decades and with advances in diagnosis and treatment, the median survival reaches beyond 5 years [3]. With further exploration of treatment for HCC, overall survival (OS) as a standard endpoint to evaluate the efficacy of treatment is complicated, because it requires a large number of patients and longer follow-up period. It is necessary and meaningful to explore a reliable surrogate endpoint for OS to allow early assessment of treatment for $\mathrm{HCC}$
Treatment of $\mathrm{HCC}$ has changed greatly within the past decades and become a major research area [3]. For the treatment of HCC, surgical resection, liver transplantation and local ablative therapy are considered to be the curative treatment [4]. Surgical resection is preferred choice for HCC without cirrhosis [3]. HCC patients with normal concentration of bilirubin and no portal hypertension, the probability that survival time reaches 5 years is $70 \%$ after surgical resection [5]. Radiofrequency ablation (RFA) is commonly recommended as a first line local ablative therapy for tumors less than $5 \mathrm{~cm}$ [3]. After RFA, survival in Child-Pugh A patients was $50-75 \%$ at 5 years $[6,7]$. In addition, transarterial chemoembolization (TACE) and interferon (IFN) as the non-curative treatments have been confirmed to improve survival $[8,9]$. TACE induces objective responses in 35\% patients and improves 2-year 
survival $[8,10]$. It has been confirmed that IFN decreased the rates of tumor recurrence and mortality for hepatitis $\mathrm{B}$ virus (HBV) or/and hepatitis $\mathrm{C}$ virus (HCV) related HCC $[9,11]$. Pre- and post-operative antiviral and antiinflammatory treatment with IFN has been shown to reduce early and late tumor recurrence rates in $\mathrm{HCC}$ patients with HBV or/and HCV infection $[11,12]$. In order to find out more effective treatment to improve survival, the combined utilization of adjuvant therapy after curative treatment has attracted increasing attention. Meanwhile, it requires strict evaluation criteria to study the effect of adjuvant therapies.

Overall survival as the gold standard endpoint being used to assess the effect of HCC treatment is reliable. However, it requires a large number of patients and longer follow-up period to estimate significant differences between groups of patients [13]. Utilization of a surrogate endpoint at an early stage in clinical trials could speed up assessment of efficacy and reduce costs. It was defined that $\mathrm{OS}$ is the time from randomization to death from any cause, and disease-free survival (DFS) was the time from randomization to the first event (loco-regional, distant recurrence, or death from any cause) after treatment [14]. Recent studies had confirmed that DFS is a valid surrogate endpoint for OS in the clinical trials for the treatment of colon cancer, gastric cancer, and lung cancer [14-16]. However, there is still no available surrogate endpoint for OS to assess the efficacy of adjuvant therapies in HCC study. The purpose of our study was to evaluate whether DFS could be used as an early surrogate endpoint in studies involving adjuvant therapies after curative treatment for HCC patients.

\section{RESULTS}

This study is based on the individual study data of 2211 patients in 17 studies that were included in 8 meta-analyses. The main characteristics about 7 metaanalyses for RFA + TACE vs. RFA and 1 meta-analysis for curative treatment + IFN vs. curative treatment were summarized (Table 1). After reviewing 116 trials including 10069 patients from 7 meta-analyses, repeated trials and patients, as well as the studies failed to get HRs for OS and DFS were excluded, 7 trials containing 1042 patients were conformed to the inclusion criteria for RFA + TACE vs. RFA (Table 2). The main characteristics were summarized in Table 2. For curative treatment + IFN vs. curative treatment, 10 trials containing 1169 patients were conformed to the inclusion criteria after elimination of unqualified and duplicate data (Table 3). The main characteristics were summarized in Table 3. The HRs for OS and DFS were either obtained directly or through the Kaplan-Meier survival curves in these studies.

For treatment with RFA + TACE vs. RFA trials, a total of 7 trials containing 1042 patients were available for analysis. High correlation between the treatment effects on DFS and OS was observed, with a rank-correlation coefficient $\rho$ equaled to 0.988 (95\% CI, 0.965-0.996; Figure 1A). The 10 curative treatment-based trials (curative treatment and combination IFN) containing 1169 patients exhibited a high correlation between treatment effects on DFS and OS, with a rank-correlation coefficient $\rho$ equaled to 0.930 (95\% CI, 0.806-0.976; Figure 1B).

According to the individual study data from 17 trials, the HRs on the endpoints was appraised. Linear regression analysis was carried out to analyze the correlation between treatment effects on DFS and OS in RFA + TACE $v s$. RFA trials and curative treatment + IFN $v S$. curative treatment trials, respectively, and it revealed strong correlation between DFS and OS (Figure 2A, 2B). The correlation coefficient $\mathrm{R}$ between the HRs were 0.815 (95\% CI 0.536-0.934) for RFA + TACE vs. RFA (Figure 2A), and 0.854 (95\% CI 0.621-0.948) for curative treatment + IFN $v s$. curative treatment (Figure 2B).

Based on the linear model, as the minimum treatment effect on the surrogate endpoint (DFS), the surrogate threshold effects (STE) is necessary to calculate for predicting a non-zero effect on OS. The STE (based on the estimation error adjusted prediction limits) for RFA + TACE vs. RFA alone corresponded to a DFS HR of 0.33 (for a beneficial treatment) or 0.99 (for a harmful treatment; Figure 2A). In addition, for curative treatment + IFN vs. curative treatment alone, the STE corresponded to a DFS HR of 0.87 (for a beneficial treatment) or 1.44 (for a harmful treatment; Figure 2B).

The prediction results from the leave-one-out crossvalidation analysis showed that for DFS, the observed HRs for OS fell between the limits of the 95\% prediction intervals in 6 of the 7 studies for RFA + TACE vs. RFA alone and 9 of the 10 studies for curative treatment + IFN $v s$. curative treatment alone (Figure 3A, 3B).

\section{DISCUSSION}

Fast progress and improvement in treatment has prolonged survival of patients with HCC. However, the best treatment for patients with different stages of HCC remains to be explored. There is no doubt that the best endpoint to be used in these studies is OS, but it requires a longer follow-up period. It has been reported that the time to progression (TTP), closely related to DFS, could be used as a surrogate endpoint for OS in the clinical trials of advanced HCC [42]. In present study, our results showed that the effects of treatment on DFS and OS were strongly correlated in the HCC patients treated with curative treatment (surgical resection and ablation) combined with or without TACE and IFN. Both the correlation coefficient $\mathrm{R}$ (trial-level) and the rank-correlation coefficient $\rho$ (individual-level) are close to 1 between DFS and OS in these patients, thus DFS is a validated surrogate endpoint 
Table 1: The eligible eight meta-analyses included in this study

\begin{tabular}{|c|c|c|c|c|c|c|}
\hline Year & Author & Content of study & $\begin{array}{l}\text { Type of studies } \\
\text { included }\end{array}$ & $\begin{array}{l}\text { No. of } \\
\text { studies }\end{array}$ & $\begin{array}{c}\text { No. of } \\
\text { patients }\end{array}$ & Type of data \\
\hline 2014 & Gu L [17] & $\begin{array}{c}\text { TACE + RFA/PEI/HIFU/ } \\
\text { PAI vs. TACE/RFA }\end{array}$ & RCT, CS & 18 & 2120 & $\mathrm{RR}$ \\
\hline 2014 & Jiang G [18] & RFA + TACE $v s$. RFA & RCT, CS & 19 & 1728 & OR \\
\hline 2014 & Kong QF [19] & RFA + TACE $v$ s. RFA & $\mathrm{RCT}, \mathrm{CS}$ & 19 & 1728 & OR \\
\hline 2013 & Lu Z [20] & RFA + TACE $v$ s. RFA & RCT & 7 & 574 & OR \\
\hline 2013 & Liao M [21] & $\begin{array}{c}\text { TACE+RFA/PEI/RT/ } \\
\text { 3D-CRT/HIFU vs. TACE }\end{array}$ & RCT, PS, RS & 28 & 1815 & $\mathrm{RR}$ \\
\hline 2013 & Ni JY [22] & $\begin{array}{c}\text { RFA + TACE } v s . \text { RFA/ } \\
\text { TACE }\end{array}$ & $\mathrm{RCT}$ & 6 & 376 & OR \\
\hline 2012 & Yan S [23] & RFA + TACE $v s$. RFA & $\mathrm{RCT}, \mathrm{CS}$ & 19 & 1728 & $\mathrm{OR}$ \\
\hline 2014 & Zhang W [24] & $\mathrm{CT}+\mathrm{IFN} v s . \mathrm{CT}$ & $\mathrm{RCT}, \mathrm{CCS}$ & 14 & 1835 & $\mathrm{RR}$ \\
\hline
\end{tabular}

RCT: randomized controlled trial; PS: prospective study; RS: retrospective study; CS: cohort study; CCS: case-control study; OR: odds ratio; RR: risk ratio; RFA: radiofrequency ablation; TACE: transcatheter arterial chemoembolization; PEI: percutaneous ethanol injection; PAI: percutaneous acetic acid; HIFU: high-intensity focused ultrasound; 3D-CRT: threedimensional conformal radiation therapy; CT: curative treatment; IFN: interferon.

Table 2: The trials for RFA + TACE vs. RFA

\begin{tabular}{|c|c|c|c|c|c|c|}
\hline \multirow{2}{*}{ Year } & \multirow{2}{*}{ Author } & \multirow{2}{*}{ Type of study } & \multicolumn{3}{|c|}{ No. of patients } & \multirow{2}{*}{ Follow-up (months) } \\
\hline & & & RFA & & Total & \\
\hline 2013 & Peng ZW [25] & $\mathrm{RCT}$ & 94 & 95 & 189 & $7-62$ \\
\hline 2012 & Kim JW [26] & $\mathrm{RS}$ & 83 & 231 & 314 & $0-108$ \\
\hline 2012 & Peng ZW [27] & $\mathrm{RCT}$ & 69 & 70 & 139 & $0-103$ \\
\hline 2010 & Morimoto M [28] & $\mathrm{RCT}$ & 19 & 18 & 37 & $12-46$ \\
\hline 2010 & Peng ZW [29] & $\mathrm{CCS}$ & 120 & 120 & 240 & $0-64$ \\
\hline 2009 & Shibata T [30] & $\mathrm{RCT}$ & 46 & 43 & 89 & $9-68$ \\
\hline 2005 & Shen SQ [31] & $\mathrm{CCS}$ & 18 & 16 & 34 & $5-38$ \\
\hline
\end{tabular}

RCT: randomized controlled trial; CCS: case-control study; RS: retrospective study; RFA: radiofrequency ablation; TACE: transcatheter arterial chemoembolization.

for OS statistically [43]. These findings suggest that DFS could be used as a surrogate endpoint for OS to reduce the duration and cost in the future clinical studies.

As a reasonable candidate for a surrogate of OS, DFS has been confirmed that it is a surrogate for OS in many tumor types [14-16]. Moreover, it has been reported that DFS was the preferred potential surrogate endpoint for small HCC according to a questionnaires survey among clinicians and methodologists [44]. Our study confirmed that DFS could be used as a surrogate endpoint for OS to accelerate assessment of efficacy for adjuvant therapy after curative treatment in HCC. These results were based on a re-analysis of meta-analyses of individual patients' data.

It was reported that surgical resection, liver transplantation, or ablation were curative treatment for
HCC patients [3]. Meanwhile, an increasing number of adjuvant therapies were used to treat $\mathrm{HCC}$ patients. There was no HCC patient with liver transplantation included in this study because of few published study was consistent with our inclusion criteria. In addition, a lot of studies about adjuvant therapies did not provide the HR, and part of studies was not analyzed by using Kaplan-Meier survival curves and the data couldn't be extracted to calculate the HR. TACE and IFN were commonly used as adjuvant therapies after curative treatment for HCC patients nowadays. The majority of trials about TACE and IFN were conformed to the inclusion criteria. This study analyzed the published data of patients with HCC who received curative RFA combined with TACE $v s$. RFA alone, and curative 
Table 3: The trials for CT + IFN vs. CT

\begin{tabular}{lcccccc}
\hline \multirow{2}{*}{ Year } & \multirow{2}{*}{ Author } & \multirow{2}{*}{ Type of study } & \multicolumn{3}{c}{ No. of patients } & \multirow{2}{*}{ Follow-up (months) } \\
\cline { 4 - 6 } & Chen LT [32] & RCT & 133 & 135 & 268 & $0-66.9$ \\
2012 & Hagihara H [33] & CCT & 37 & 145 & 182 & $0-120$ \\
2011 & Lo C M [34] & RCT & 40 & 40 & 80 & $0-160$ \\
2007 & Jeong SC [35] & CCT & 42 & 42 & 84 & $0-144$ \\
2007 & Jeong SC [36] & CCT & 16 & 16 & 32 & $0-45$ \\
2007 & Kudo M [37] & CCT & 43 & 84 & 127 & $0-100$ \\
2007 & Sun HC [38] & RCT & 118 & 118 & 236 & $0-68$ \\
2006 & Shiratori Y [39] & RCT & 49 & 25 & 74 & $0-108$ \\
2003 & Miyaguchi S [40] & CCT & 22 & 24 & 46 & $0-45$ \\
2002 & Suou T [41] & CCT & 18 & 22 & 40 & $0-110$ \\
2001 &
\end{tabular}

RCT: randomized controlled trial; CCT: case-cohort study; CT: curative treatment; IFN: interferon.

treatment (surgical resection and ablation) combined with IFN $v s$. curative treatment alone.

Furthermore, cross-validation results confirmed the accurate prediction of treatment effect on OS is based on the effects on DFS for RFA + TACE $v s$. RFA and curative treatment + IFN vs. curative treatment. Using the STE obtained from our study to predict a non-zero treatment effect on OS, it would require the upper limit of the CI of the estimated HR to fall below 0.33 , or the lower limit to be above 0.99 for RFA + TACE vs. RFA, and the upper limit of the CI of the estimated HR to fall below 0.87 , or the lower limit to be above 1.44 for curative treatment + IFN vs. curative treatment. Although, both of them are wide interval for HR, the DFS as a surrogate endpoint for OS remains to be validated and it could be a better choice for the study of adjuvant therapy in HCC.

There are a few limitations to our analysis because it was based on the data extracted from literature, rather than based on the data of each patient directly. Our study included 17 trials from 8 meta-analyses, and the data extracted from Kaplan-Meier survival curves was used to calculate HRs according to a reliable method. Furthermore, with increasing clinical trials of adjuvant therapies for $\mathrm{HCC}$, more work remains to be done to analyze the surrogacy of DFS for OS in upcoming study.

In conclusion, our results suggested that DFS could be used as a surrogate endpoint for OS to allow early assessment of efficacy of adjuvant therapies after curative treatment for HCC patients in future clinical trials.

\section{MATERIALS AND METHODS}

\section{Search strategy and selection criteria}

As presented previously [43], the search strategy was divided into two steps. First, a comprehensive
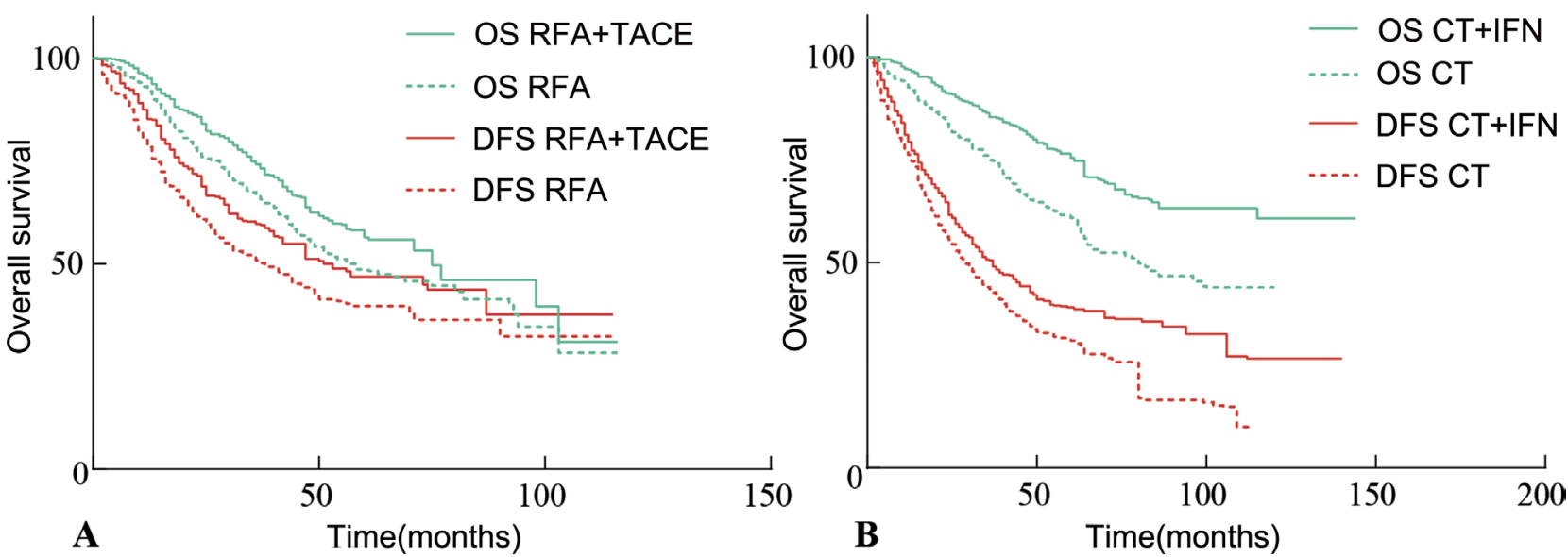

Figure 1: Kaplan-Meier curves of DFS and OS in assessment the effect of adjuvant therapies after curative treatment for HCC patients. (A) Assessment of RFA + TACE vs. RFA. (B) Assessment of curative treatment + IFN vs. curative treatment. OS = overall survival. $\mathrm{RFA}=$ Radiofrequency ablation. $\mathrm{TACE}=$ Transarterial chemoembolization. $\mathrm{DFS}=$ disease-free survival. $\mathrm{CT}=$ curative treatment. 


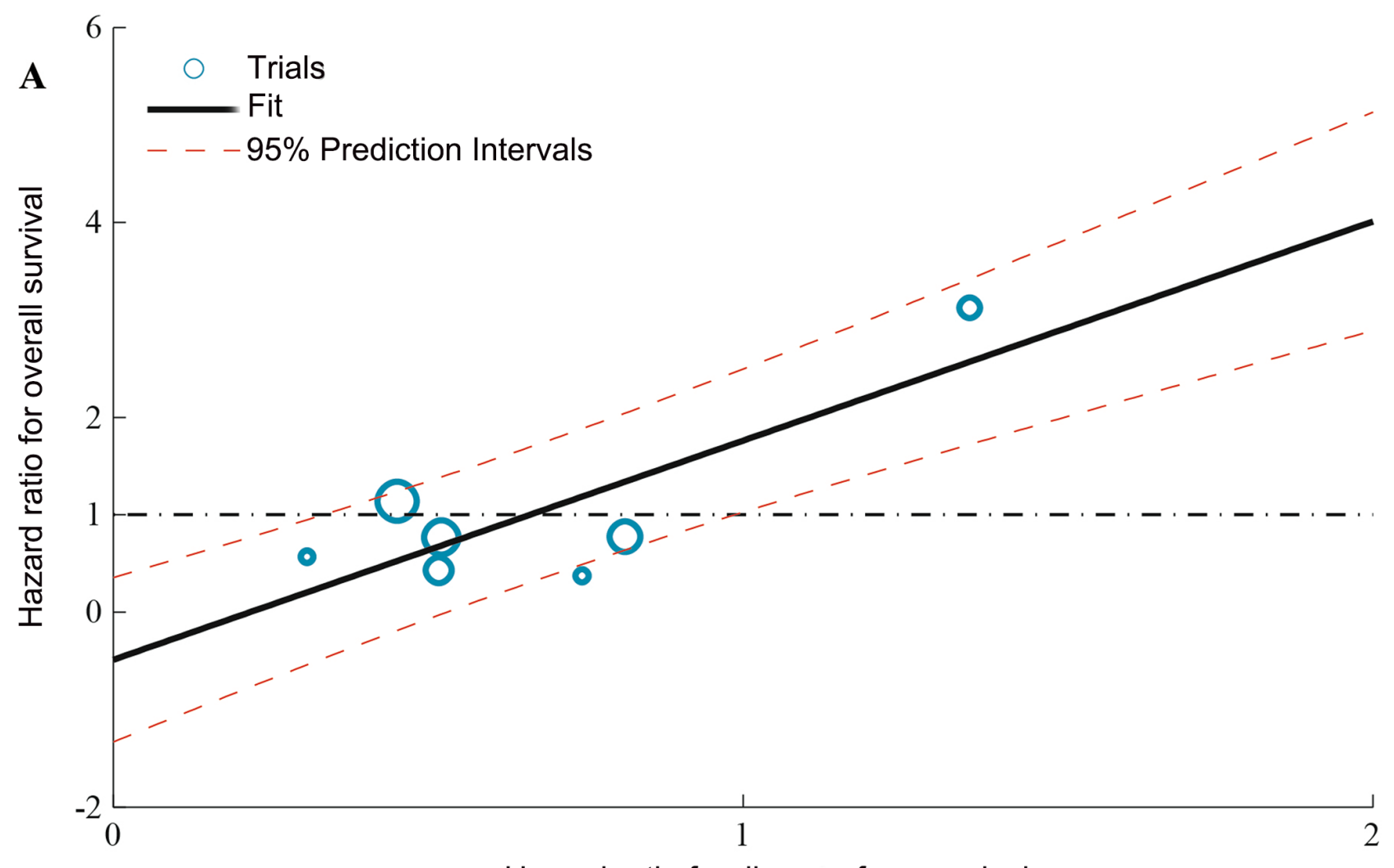

Hazard ratio for disease-free survival

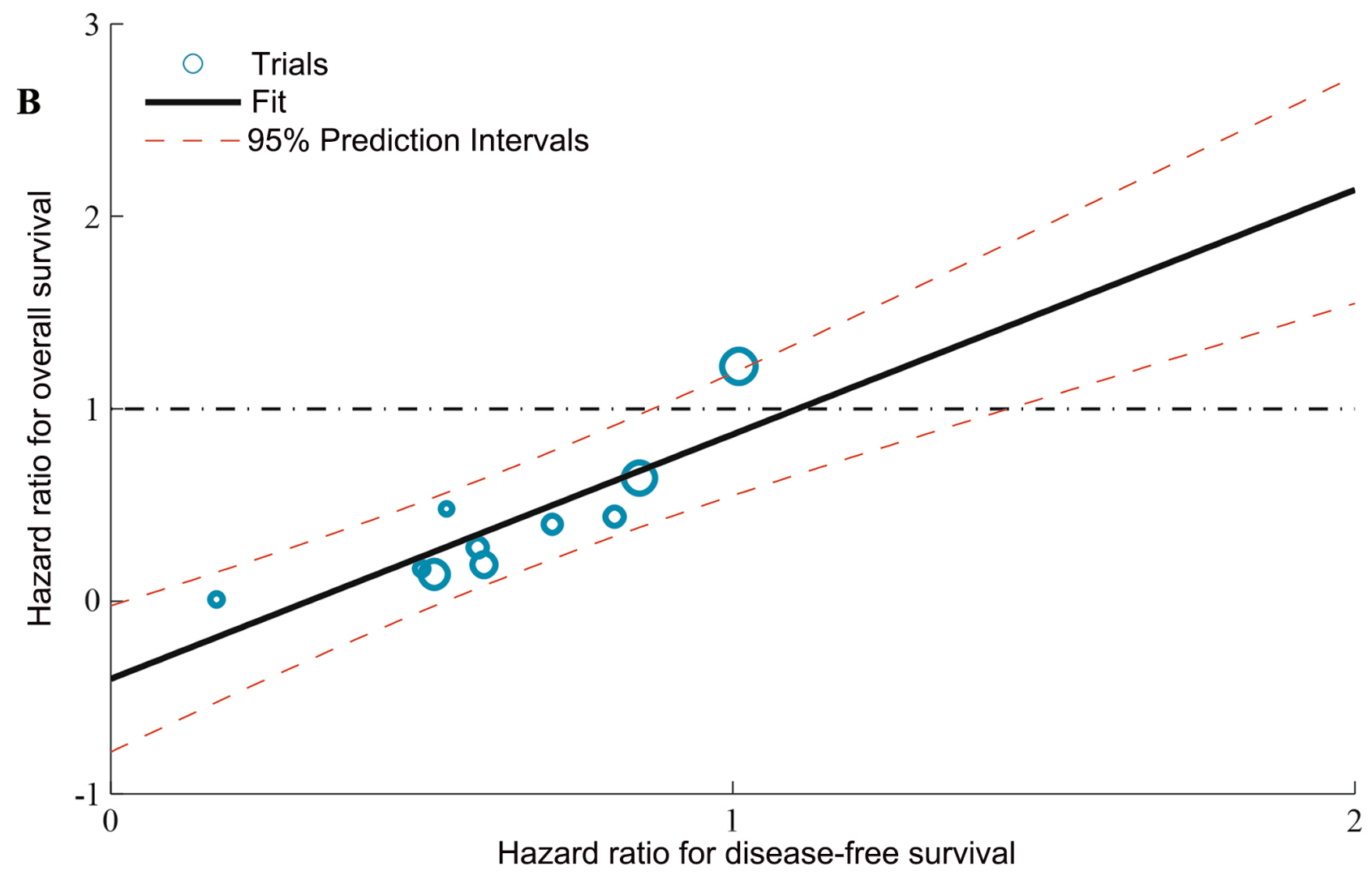

Figure 2: Correlation between treatment effects on DFS and OS. (A) Assessment of RFA + TACE vs. RFA. (B) Assessment of curative treatment + IFN vs. curative treatment. Each trial is represented by a circle with a size proportional to the number of patients. The black solid line corresponds to the fitted regression line and the red dashed lines correspond to $95 \%$ CI. Correlation values are good $(\mathrm{R}=0.815$ and 0.854$)$. $\mathrm{CT}=$ curative treatment. 

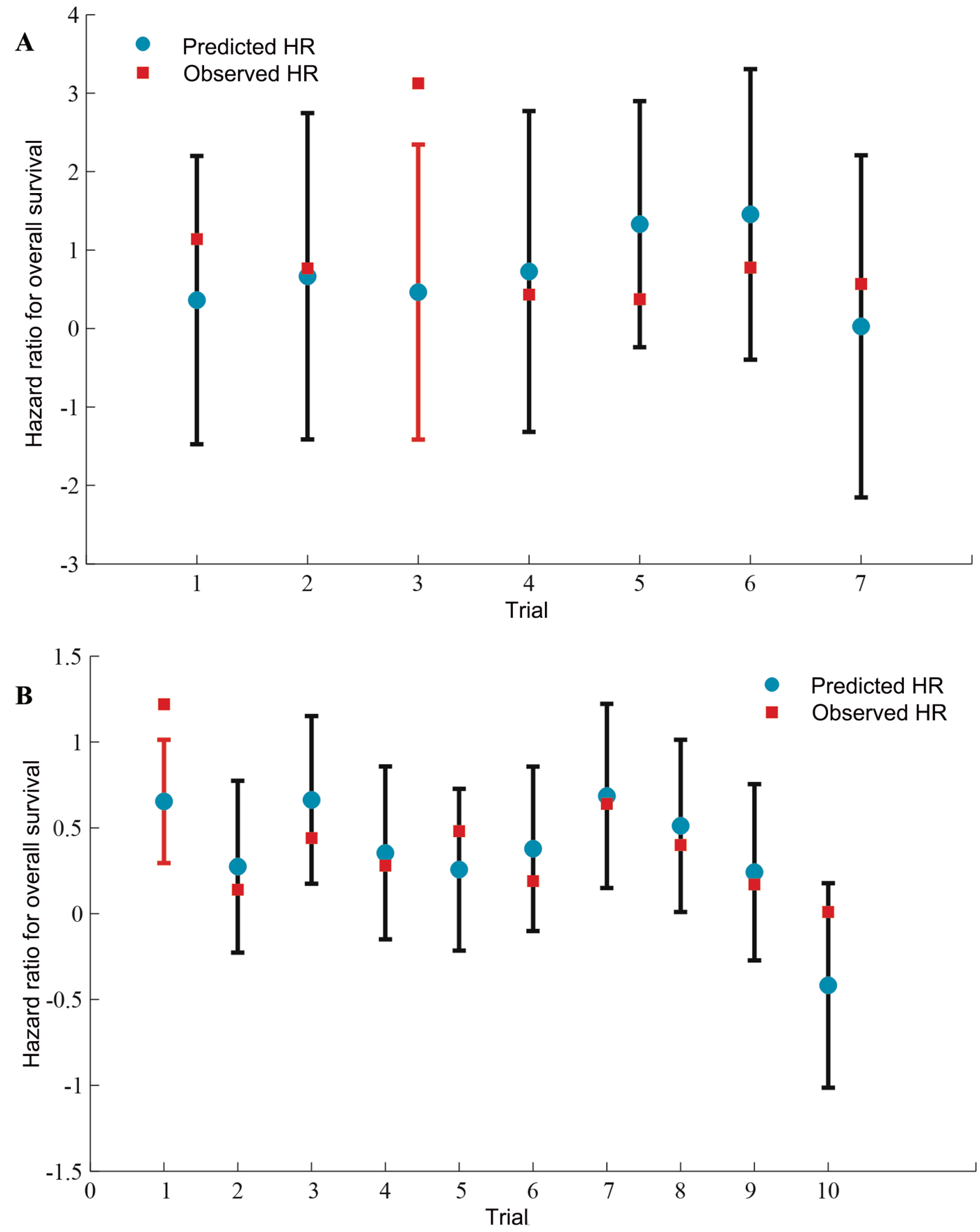

Figure 3: Internal validation of the prediction of OS by treatment effects on surrogate endpoints. (A) Assessment of RFA + TACE vs. RFA. (B) Assessment of curative treatment + IFN vs. curative treatment. The blue circles correspond to the predicted hazard ratios for overall survival using the observed hazard ratio on disease-free survival of that particular trial and the surrogate model built on all the other trials; vertical lines correspond to $95 \%$ prediction intervals; the red squares correspond to observed hazard ratios on overall survival; Predicted values from trials for which observed hazard ratios are outside the limits are in red. $\mathrm{HR}=$ hazard ratio. $\mathrm{CT}=$ curative treatment. 
automated literature search was carried out in Biosis, Embase and PubMed Databases for meta-analyses on randomized controlled trials or retrospective cohort studies that compared RFA plus TACE with RFA alone, and curative treatment plus IFN with curative treatment alone, in HCC patients. The literature search used the terms "curative treatment", "surgical resection", "ablation", "RFA", "TACE", "interferon", and "liver cancer" or "HCC" for studies that were published between January, 2000, and December, 2015. Eligible metaanalyses were included following the flow diagram of the PRISMA (Preferred Reporting items for Systematic Reviews and Meta-analysis) Group (2009). Second, the studies were further selected using the following inclusion criteria: (a) studies reported in English; (b) randomized controlled trials or retrospective cohort studies comparing RFA plus TACE with RFA alone, and curative treatment plus IFN with curative treatment alone for HCC; and (c) studies providing data on hazard ratios (HRs) for OS and DFS, and for those studies not providing HRs, published Kaplan-Meier survival curves of OS and DFS. Noncomparative studies that investigated IFN, RFA or TACE for HCC were excluded. The literature search and studies selection were carried out by two independent researchers. If there were any disagreements, a third researcher would decide whether the study should be included.

\section{Surrogacy criteria}

DFS was defined as the time from randomization to the first event (loco-regional, distant recurrence, or death from any cause) after treatment. OS was defined as the time from randomization to death from any cause [14]. The surrogacy criteria were used by Marc Buyse et al. in this study [45]. The approach was based on the strength of association between the surrogate and the true endpoint (the individual-study-level surrogacy) and between the effects of treatment on the surrogate and the true endpoint (the trial-level surrogacy).

\section{Statistical analysis}

Statistical analyses were carried out using the Matlab version R2011a and SPSS version 21.0. For each study, we extracted the data of HR $(95 \% \mathrm{CI})$ for DFS and OS. If the study did not provide the HRs, we extracted the data from the Kaplan-Meier survival curves and calculated the HRs using the method by Jayne F Tierney et al. [46].

The association between the distribution of the true endpoint (OS) and the surrogate endpoint (DFS) was assessed by a bivariate survival model at the individual-level. To quantify the association between the effect of treatment on OS and the effect of treatment on DFS, a linear regression model was used at the triallevel. Treatment effects were estimated by hazard ratios
(HRs). We classified correlation values higher than 0.9 as excellent, higher than 0.75 as very good, higher than 0.5 as good, higher than 0.25 as moderate, and equal to or lower than 0.25 as poor.

On the basis of the linear model at the second stage of the two-stage approach, we calculated the surrogate threshold effect (STE), which was defined as the minimum treatment effect on the surrogate (DFS) necessary to predict a non-zero effect on the true endpoint (OS), i.e. the HR was not equal to 1. A future trial requires an upper limit of a confidence interval for the estimated treatment effect (HR) of the surrogate to fall below the STE to predict a non-zero effect on OS, as described previously [47].

For each meta-analysis, we used a leave-one-out cross-validation approach to assess the prediction accuracy of the surrogate model. Each study was left out once and the linear model was rebuilt with the other studies. This model was then applied to the left-out study and a 95\% prediction interval was calculated to compare the predicted and the observed treatment effect on OS.

\section{List of abbreviations}

Hepatocellular carcinoma (HCC); Overall survival (OS); Disease-free survival (DFS); Surrogate threshold effect (STE); Hepatitis B virus (HBV); Hepatitis C virus (HCV); Hazard ratio (HR); Odds ratio (OR); Risk ratio (RR); Radiofrequency ablation (RFA); Transarterial chemoembolization (TACE); Curative treatment (CT); interferon (IFN); High-intensity focused ultrasound (HIFU); Confidence interval (CI); Randomized controlled trial (RCT); Prospective study (PS); Retrospective study (RS); Cohort study (CS); Case-controlled trial (CCT:); Percutaneous ethanol injection (PEI); Percutaneous acetic acid (PAI); Threedimensional conformal radiation therapy (3D-CRT); case-control study (CCS).

\section{Authors' contributions}

Study concept and design: Xia and Wu; acquisition of data: Wu, Huan, Wang and Wen; analysis and interpretation of data: Wu, Xia, Zhang and Yang; drafting of the manuscript: $\mathrm{Wu}$, Huan and Lau; critical revision of the manuscript for important intellectual content: Xia, Lau and Bie; statistical analysis: Wu and Huan; obtained funding and study supervision: Xia.

\section{CONFLICTS OF INTEREST}

Authors who have taken part in this study declared that they do not have anything to disclose regarding funding or conflict of interest with respect to this manuscript. 


\section{FUNDING}

This work was supported by the grant of Key Laboratory of Tumor Immunology and Pathology of Ministry of Education (NO.2012jsz108) and National Natural Science Foundation of China (No. 81272224).

\section{REFERENCES}

1. Torre LA, Bray F, Siegel RL, Ferlay J, Lortet-Tieulent J, Jemal A. Global cancer statistics, 2012. CA Cancer J Clin. 2015; 65:87-108.

2. Perz JF, Armstrong GL, Farrington LA, Hutin YJ, Bell BP. The contributions of hepatitis $\mathrm{B}$ virus and hepatitis $\mathrm{C}$ virus infections to cirrhosis and primary liver cancer worldwide. J Hepatol. 2006; 45:529-38.

3. Forner A, Llovet JM, Bruix J. Hepatocellular carcinoma. Lancet. 2012; 379:1245-55.

4. Bruix J, Sherman M, American Association for the Study of Liver Diseases. Management of hepatocellular carcinoma: an update. Hepatology. 2011; 53:1020-2.

5. Ishizawa T, Hasegawa K, Aoki T, Takahashi M, Inoue Y, Sano K, Imamura H, Sugawara Y, Kokudo N, Makuuchi M. Neither multiple tumors nor portal hypertension are surgical contraindications for hepatocellular carcinoma. Gastroenterology. 2008; 134:1908-16.

6. Lencioni R. Loco-regional treatment of hepatocellular carcinoma. Hepatology. 2010; 52: 762-73.

7. Germani G, Pleguezuelo M, Gurusamy K, Meyer T, Isgro G, Burroughs AK. Clinical outcomes of radiofrequency ablation, percutaneous alcohol and acetic acid injection for hepatocelullar carcinoma: a meta-analysis. J Hepatol. 2010; 52:380-88.

8. Llovet JM, Bruix J. Systematic review of randomized trials for unresectable hepatocellular carcinoma: Chemoembolization improves survival. Hepatology. 2003; 37:429-42.

9. Shen YC, Hsu C, Chen LT, Cheng CC, Hu FC, Cheng AL. Adjuvant interferon therapy after curative therapy for hepatocellular carcinoma (HCC): a meta-regression approach. J Hepatol. 2010; 52:889-94.

10. Llovet JM, Real MI, Montaña X, Planas R, Coll S, Aponte J, Ayuso C, Sala M, Muchart J, Solà R, Rodés J, Bruix J; Barcelona Liver Cancer Group. Arterial embolisation or chemoembolisation versus symptomatic treatment in patients with unresectable hepatocellular carcinoma: a randomised controlled trial. Lancet. 2002; 359:1734-9.

11. Miyake Y, Takaki A, Iwasaki Y, Yamamoto K. Metaanalysis: interferon-alpha prevents the recurrence after curative treatment of hepatitis $\mathrm{C}$ virus-related hepatocellular carcinoma. J Viral Hepat. 2010; 17:287-92.

12. Hoshida Y. Risk of recurrence in hepatitis B-related hepatocellular carcinoma: impact of viral load in late recurrence. J Hepatol. 2009; 51:842-4.
13. Michiels S, Le Maître A, Buyse M, Burzykowski T, Maillard E, Bogaerts J, Vermorken JB, Budach W, Pajak TF, Ang KK, Bourhis J, Pignon JP, MARCH and MACH-NC Collaborative Groups. Surrogate endpoints for overall survival in locally advanced head and neck cancer: metaanalyses of individual patient data. Lancet Oncol. 2009; 10:341-50.

14. Sargent DJ, Wieand HS, Haller DG, Gray R, Benedetti JK, Buyse M, Labianca R, Seitz JF, O'Callaghan CJ, Francini G, Grothey A, O'Connell M, Catalano PJ, et al. Disease-Free Survival Versus Overall Survival As a Primary End Point for Adjuvant Colon Cancer Studies: Individual Patient Data From 20,898 Patients on 18 Randomized Trials. J Clin Oncol. 2005; 23:8664-70.

15. Oba K, Paoletti X, Alberts S, Bang YJ, Benedetti J, Bleiberg H, Catalano P, Lordick F, Michiels S, Morita S, Ohashi Y, Pignon JP, Rougier P, et al. Disease-Free survival as a surrogate for Overall survival in Adjuvant Trials of Gastric Cancer: A Meta-Analysis. J Natl Cancer Inst. 2013; 105:1600-7.

16. Mauguen A, Pignon JP, Burdett S, Domerg C, Fisher D, Paulus R, Mandrekar SJ, Belani CP, Shepherd FA, Eisen T, Pang H, Collette L, Sause WT, et al. Surrogate endpoints for overallsurvival in chemotherapy and radiotherapy trials in operable and locally advanced lung cancer: a re-analysis of meta-analyses of individual patients' data. Lancet Oncol. 2013; 14:619-626.

17. Gu L, Liu H, Fan L, Lv Y, Cui Z, Luo Y, Liu Y, Li G, Li C, Ma J. Treatment outcomes of transcatheter arterial chemoembolization combined with local ablative therapy versus monotherapy in hepatocellular carcinoma: a metaanalysis. J Cancer Res Clin Oncol. 2014; 140:199-210.

18. Jiang $\mathrm{G}, \mathrm{Xu} \mathrm{X}$, Ren S, Wang L. Combining transarterial chemoembolization with radiofrequency ablation for hepatocellular carcinoma. Tumour Biol. 2014; 35:3405-3408.

19. Kong QF, Jiao JB, Chen QQ, Li L, Wang DG, Lv B. Comparative effectiveness of radiofrequency ablation with or without transarterial chemoembolization for hepatocellular carcinoma. Tumour Biol. 2014; 35:2655-9.

20. Lu Z, Wen F, Guo Q, Liang H, Mao X, Sun H. Radiofrequency ablation plus chemoembolization versus radiofrequency ablation alone for hepatocellular carcinoma: a meta-analysis of randomized-controlled trials. Eur J Gastroenterol Hepatol. 2013; 25:187-194.

21. Liao $M$, Huang J, Zhang $\mathrm{T}$, $\mathrm{Wu} \mathrm{H}$. Transarterial Chemoembolization in Combination with Local Therapies for Hepatocellular Carcinoma: A Meta-Analysis. PLoS One. 2013; 8:e68453.

22. Ni JY, Liu SS, Xu LF, Sun HL, Chen YT. Transarterial chemoembolization combined with percutaneous radiofrequency ablation versus TACE and PRFA monotherapy in the treatment for hepatocellular carcinoma: a meta-analysis. J Cancer Res Clin Oncol. 2013; 139:653-659. 
23. Yan S, Xu D, Sun B. Combination of Radiofrequency Ablation with Transarterial Chemoembolization for Hepatocellular Carcinoma: A Meta-Analysis. Dig Dis Sci. 2012; 57:3026-3031.

24. Zhang W, Song TQ, Zhang T, Wu Q, Kong DL, Li Q, Sun HC. Adjuvant interferon for early or late recurrence of hepatocellular carcinoma and mortality from hepatocellular carcinoma following curative treatment: A meta-analysis with comparison of different types of hepatitis. Mol Clin Oncol. 2014; 2:1125-1134.

25. Peng ZW, Zhang YJ, Chen MS, Xu L, Liang HH, Lin XJ, Guo RP, Zhang YQ, Lau WY. Radiofrequency ablation with or without transcatheter arterial chemoembolization in the treatment of hepatocellular carcinoma: a prospective randomized trial. J Clin Oncol. 2013; 31:426-432.

26. Kim JW, Kim JH, Won HJ, Shin YM, Yoon HK, Sung KB, Kim PN. Hepatocellular carcinomas $2-3 \mathrm{~cm}$ in diameter: transarterial chemoembolization plus radiofrequency ablation vs. radiofrequency ablation alone. Eur J Radiol. 2012; 81:e189-93.

27. Peng ZW, Zhang YJ, Liang HH, Lin XJ, Guo RP, Chen MS. Recurrent hepatocellular carcinoma treated with sequential transcatheter arterial chemoembolization and RF ablation versus RF ablation alone: a prospective randomized trial. Radiology. 2012; 262:689-700.

28. Morimoto M, Numata K, Kondou M, Nozaki A, Morita S, Tanaka K. Midterm outcomes in patients with intermediatesized hepatocellular carcinoma: a randomized controlled trial for determining the efficacy of radiofrequency ablation combined with transcatheter arterial chemoembolization. Cancer. 2010; 116:5452-60.

29. Peng ZW, Chen MS, Liang HH, Gao HJ, Zhang YJ, Li JQ, Zhang YQ, Lau WY. A case-control study comparing percutaneous radiofrequency ablation alone or combined with transcatheter arterial chemoembolization for hepatocellular carcinoma. Eur J Surg Oncol. 2010; 36:257-263.

30. Shibata T, Isoda H, Hirokawa Y, Arizono S, Shimada K, Togashi K. Small hepatocellular carcinoma: is radiofrequency ablation combined with transcatheter arterial chemoembolization more effective than radiofrequency ablation alone for treatment? Radiology. 2009; 252:905-13.

31. Shen SQ, Xiang JJ, Xiong CL, Wu SM, Zhu SS. Intraoperative radiofrequency thermal ablation combined with portal vein infusion chemotherapy and transarterial chemoembolization for unresectable HCC. Hepatogastroenterology. 2005; 52:1403-7.

32. Chen LT, Chen MF, Li LA, Lee PH, Jeng LB, Lin DY, Wu CC, Mok KT, Chen CL, Lee WC, Chau GY, Chen YS, Lui WY, et al. Long-term results of a randomized, observation-controlled, phase III trial of adjuvant interferon Alfa-2b in hepatocellular carcinoma after curative resection. Ann Surg. 2012; 255:8-17.

33. Hagihara H, Nouso K, Kobayashi Y, Iwasaki Y, Nakamura S, Kuwaki K, Toshimori J, Miyatake H, Ohnishi H, Shiraha H,
Yamamoto K. Effect of pegylated interferon therapy on intrahepatic recurrence after curative treatment of hepatitis $\mathrm{C}$ virus-related hepatocellular carcinoma. Int J Clin Oncol. $2011 ; 16: 210-20$.

34. Lo CM, Liu CL, Chan SC, Lam CM, Poon RT, Ng IO, Fan ST, Wong J. A randomized, controlled trial of postoperative adjuvant interferon therapy after resection of hepatocellular carcinoma. Ann Surg. 2007; 245:831-42.

35. Jeong SC, Aikata H, Katamura Y, Azakami T, Kawaoka T, Saneto H, Uka K, Mori N, Takaki S, Kodama H, Waki K, Imamura M, Shirakawa $H$, et al. Effects of a 24-week course of interferon-alpha therapy after curative treatment of hepatitis $\mathrm{C}$ virus-associated hepatocellular carcinoma. World J Gastroenterol. 2007; 13:5343-50.

36. Jeong SC, Aikata H, Katamura Y, Azakami T, Kawaoka T, Saneto H, Uka K, Mori N, Takaki S, Kodama H, Waki K, Imamura M, Shirakawa $\mathrm{H}$, et al. Low-dose intermittent interferon-alpha therapy for HCV-related liver cirrhosis after curative treatment of hepatocellular carcinoma. World J Gastroenterol. 2007; 13:5188-95.

37. Kudo M, Sakaguchi Y, Chung H, Hatanaka K, Hagiwara S, Ishikawa E, Takahashi S, Kitai S, Inoue T, Minami Y, Ueshima K. Long-term interferon maintenance therapy improves survival in patients with HCV-related hepatocellular carcinoma after curative radiofrequency ablation. A matched case-control study. Oncology. 2007; 72:132-8.

38. Sun HC, Tang ZY, Wang L, Qin LX, Ma ZC, Ye QH, Zhang BH, Qian YB, Wu ZQ, Fan J, Zhou XD, Zhou J, Qiu SJ, et al. Postoperative interferon alpha treatment postponed recurrence and improved overall survival in patients after curative resection of HBV-related hepatocellular carcinoma: a randomized clinical trial. J Cancer Res Clin Oncol. 2006; 132:458-65.

39. Shiratori Y, Shiina S, Teratani T, Imamura M, Obi S, Sato S, Koike Y, Yoshida H, Omata M. Interferon therapy after tumor ablation improves prognosis in patients with hepatocellular carcinoma associated with hepatitis $\mathrm{C}$ virus. Ann Intern Med. 2003; 138:299-306.

40. Miyaguchi S, Watanabe T, Takahashi H, Nakamura M, Saito H, Ishii H. Interferon therapy for hepatocellular carcinoma patients with low HCV-RNA levels. Hepatogastroenterology. 2002; 49:724-9.

41. Suou T, Mitsuda A, Koda M, Matsuda H, Maruyama S, Tanaka H, Kishimoto Y, Kohno M, Hirooka Y, Kawasaki H. Interferon alpha inhibits intrahepatic recurrence in hepatocellular carcinoma with chronic hepatitis C: a pilot study. Hepatol Res. 2001; 20:301-11.

42. Lee DW, Jang MJ, Lee KH, Cho EJ, Lee JH, Yu SJ, Kim YJ, Yoon JH, Kim TY, Han SW, Oh DY, Im SA, Kim TY. TTP as a surrogate endpoint in advanced hepatocellular carcinoma treated with molecular targeted therapy: metaanalysis of randomized controlled trials. Br J Cancer. 2016; 115:1201-120. 
43. Buyse M, Molenberghs G, Burzykowski T, Renard D, Geys H. The validation of surrogate endpoints in metaanalyses of randomized experiments. Biostatistics. 2000; $1: 49-67$.

44. Methy N, Bedenne L, Bonnetain F. Surrogate endpoints for overall survival in digestive oncology trials: which candidates? A questionnaires survey among clinicians and methodologists. BMC Cancer. 2010;10:277.

45. Buyse M, Burzykowski T, Michiels S, Carroll K. Individualand trial-level surrogacy in colorectal cancer. Stat Methods Med Res. 2008; 17:467-75.
46. Tierney J, Stewart LA, Ghersi D, Burdett S, Sydes MR. Practical methods for incorporating summary time-to-event data into meta-analysis. Trials 2007;8:16.

47. Burzykowski T, Buyse M. Surrogate threshold effect: an alternative measure for meta-analytic surrogate endpoint validation. Pharm Stat. 2006; 5:173-86. 